\title{
DESAFIOS DA TECNOLOGIA 5G
}

5G TECHNOLOGY CHALLENGES

\author{
Jefferson de Lucca - jeffersondelucca@outlook.com \\ Paulo Sérgio Gaudencio Mauro - paulo.mauro@fatec.sp.gov.br \\ Faculdade de Tecnologia de Catanduva (Fatec) - Catanduva - São Paulo - Brasil \\ DOI: $10.31510 /$ infa.v17i1.708
}

\section{RESUMO}

A tecnologia está em constante evolução e crescimento, atinge todas as áreas e transforma o modo como as pessoas interagem com ela. Nesse sentido pode-se afirmar que a nova geração da Internet, a Internet de quinta geração, também chamada de Internet 5G, promoverá, possivelmente, um grande impacto não somente nas organizações públicas e privadas, mas também na vida das pessoas. Esse impacto será causado, principalmente pelo fato de que a Internet móvel 5G será uma tecnologia que possibilitará a implementação da Internet das Coisas (Internet of Things - IoT) e, consequentemente, a possibilidade de alcançarmos as Cidades Inteligentes (Smarts Cities). O objetivo deste trabalho, pautado na pesquisa bibliográfica exploratória, é confirmar a necessidade de uma tecnologia com maior velocidade de transmissão e que suporte muitos dispositivos que estarão conectados num futuro breve. Também é objetivo deste trabalho, verificar o processo da regulamentação internacional e do projeto para a regulamentação da tecnologia $5 \mathrm{G}$ no Brasil e, por fim, demonstrar situações relacionadas ao possível impacto negativo dessa tecnologia para os seres vivos e para as tecnologias já em uso.

Palavras-chave: 5G. Regulamentação. Impactos. Internet das Coisas.

\begin{abstract}
Technology is constantly evolving and growing, reaching all areas and transforming the way people interact with it. In this sense, it can be said that the new Internet generation, the fifth (5G), can possibly promote a great impact not only on public and private institutions, but also on people's lives. This impact will be caused mainly to the fact that $5 \mathrm{G}$ mobile Internet is a technology that will enable Internet of Things (IoT) implementation and, consequently, the possibility of reaching Smarts Cities. The aim of this paper, which is an exploratory bibliographic research, is to show the need of a new faster transmission technology which supports a great number of connected devices in the near future. It also aims at to demonstrate international and national $5 \mathrm{G}$ technology regulation process and, lastly, it is shown possible impact of this that technology for all living beings and technologies already in use.
\end{abstract}

Keywords: 5G. Regulation. Impact. Internet of Things. 


\section{INTRODUÇÃO}

A tecnologia está evoluindo rapidamente a cada geração. Como exemplo, pode-se citar a tecnologia de rede móvel, que cada vez mais se aperfeiçoa para acompanhar as necessidades dos usuários. Desde a primeira geração - a tecnologia $1 \mathrm{G}$, até a quarta geração - a tecnologia 4G, constantes pesquisas aprimoram a qualidade do serviço e, consequentemente, a melhora dos serviços móveis oferecidos pelas operadoras de telecomunicação.

A demanda dos consumidores está moldando os serviços de banda larga móvel. Estima-se que o tráfego de dados gerado pelos usuários de dispositivos móveis estará aproximadamente cem vezes maior até o ano de 2030. Estima-se também, um aumento na quantidade de dispositivos conectados por usuários. A ITU (International Telecommunication Union) estima que esse volume atinja 50 bilhões de aparelhos conectados até 2025 e exigirá tecnologias de conectividade que suportem esta crescente demanda. (ITU, 2019, tradução nossa).

Nesse sentido, este trabalho tem como objetivo um estudo da tecnologia móvel de quinta geração, a tecnologia $5 \mathrm{G}$ móvel, no que se refere à padronização internacional e nacional, bem como evidenciar a necessidade de uma tecnologia com maior velocidade de transmissão e que suporte muitos dispositivos que estarão conectados num futuro breve e os possíveis impactos contrários do uso dessa tecnologia.

A metodologia de pesquisa utilizada neste artigo envolve pesquisa exploratória, qualitativa e analítica, que demostra o conceito dessa tecnologia. Com esta pesquisa, espera-se evidenciar a necessidade de tecnologias emergentes, o caminho para regulamentação internacional e nacional da tecnologia $5 \mathrm{G}$ e, por fim, auxiliar na compreensão e popularização do tema.

\section{TECNOLOGIA 5G}

De acordo com o site internacional ETSI (2019, tradução nossa), o tráfego de dados móveis aumenta exponencialmente, principalmente o streaming de vídeo. Além disso, em breve, cada usuário terá um número crescente de conexões, devido aos diversos dispositivos pertencentes e conectados à Internet das Coisas. Isso exigirá redes que precisam lidar com um grande volume de dispositivos conectados e uma grande demanda por maiores velocidades de 
conexão.

Ainda segundo o site ETSI (2019, tradução nossa) "A tecnologia de comunicação móvel 5G pode permitir que novos serviços sejam operacionalizados devido à latência ultrabaixa e à alta confiabilidade proporcionada por esta tecnologia. Além dos novos serviços, é também, uma possiblidade de receita para as operadoras."

O 5G é a próxima geração de tecnologia sem fio programada para chegar em 2020. Uma vez aqui, o $5 \mathrm{G}$ deve ajudar as redes sem fio a fornecer mais largura de banda, maiores velocidades de dados e menor latência para muitos outros dispositivos eletrônicos. É também um dos tópicos mais sensacionalistas da tecnologia - com entusiastas prometendo que será a porta de entrada para carros autônomos, realidade virtual e Internet das Coisas. Aqui, o IEEE Spectrum segue as notícias $5 \mathrm{G}$ de todo o mundo, à medida que as empresas de telecomunicações desenvolvem padrões, testam novas tecnologias e se preparam para distribuir 5G aos clientes (IEEESPECTRUM,2020, tradução nossa).

De acordo com o site GSMA (2018, tradução nossa), uma das possibilidades advindas da tecnologia 5G será a implementação da Internet das Coisas Massivo, o que tornará possível a implantação de cidades inteligentes (smart cities). Essa nova infraestrutura impulsiona uma série de novos modelos de negócios que mudarão o mundo de uma forma impactante.

A Figura 1 demonstra o comparativo entre a tecnologia 5G com a 4G. Nesta figura é possível observar que o tempo de download para baixar um filme, ou baixar uma hora de música ou carregar uma página web é consideravelmente reduzido.

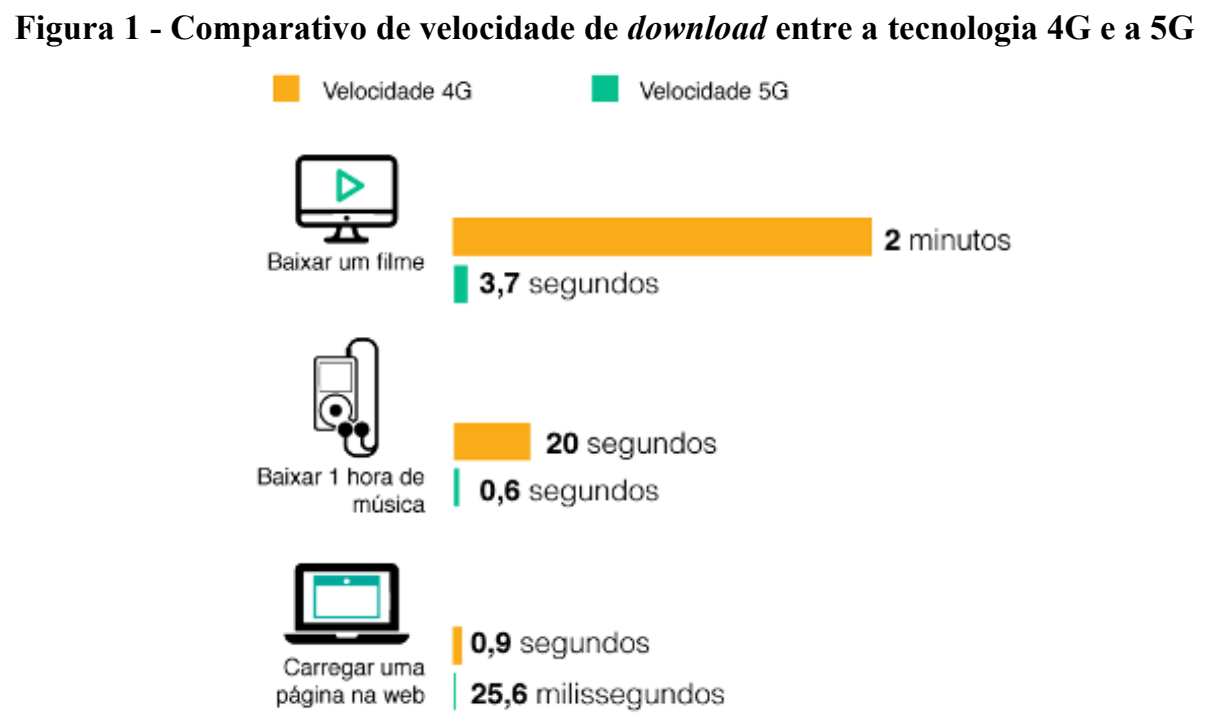

Fonte: Uol (2019)

A tecnologia 5G também deve oferecer melhorias em outros aspectos como o baixo 
consumo de energia e menor custo de operação, além de oferecer suporte a uma ampla variedade de novos aplicativos e serviços.

\subsection{Regulamentação}

Como mostrado por Lima (2018), do site Estadão, a tecnologia 5G, apesar de testes realizados por algumas operadoras de telecomunicações em alguns países, ainda não possui a sua padronização definida. A instituição que está desenvolvendo esse padrão é a ITU (International Telecommunication Union), que é uma agência ligada à ONU (Organização das Nações Unidas).

A ITU, desempenha um papel de liderança no gerenciamento do espectro de rádio e no desenvolvimento de padrões globalmente aplicáveis para o IMT-2020, nome usado na ITU para os padrões $5 \mathrm{G}$. A ITU trabalha no sentido de fornecer regulamentos internacionais para a operacionalização do IMT-2020.

Nota-se que o IMT-2020, continua a ser desenvolvido durante o ano de 2020, com ensaios $5 \mathrm{G}$ e atividades pré-comerciais em andamento para auxiliar na avaliação das tecnologias candidatas e faixas de frequência que podem ser usadas para esse fim. As primeiras implantações comerciais em larga escala para 5G são esperadas para após a finalização das especificações IMT-2020 (ITU, 2019, tradução nossa).

A padronização global, tem como objetivo padronizar as frequências utilizadas em todos os países membros, para permitir que aparelhos fabricados em um país, possam ser usados em qualquer outro, pois todos utilizarão as mesmas faixas de frequências (LIMA, 2018).

De acordo com o site Teleco (2018), a tecnologia 5G utilizará a agregação de portadoras que permitirá a alocação dinâmica das frequências. Além das frequências atuais em $700 \mathrm{MHz}, 800 \mathrm{MHz}, 900 \mathrm{MHz}, 1700 / 1800 \mathrm{MHz}, 1900 / 2100 \mathrm{MHz}$ e $2500 \mathrm{MHz}$, as seguintes faixas adicionais estão sendo consideradas:

- $3,5 \mathrm{GHz}$

- $28 \mathrm{GHz}, 37 \mathrm{GHZ}$ e $39 \mathrm{GHz}$

- 64 - $71 \mathrm{GHz}$ (não licenciada)

- $70 / 80 \mathrm{GHz}$

No entanto, cada nação tem autonomia para definir as faixas de frequências que serão utilizadas.

Segundo o site internacional GSA (2020, tradução nossa), sigla em inglês (Global 
Mobile Suppliers Association), em todo mundo, cerca de 40 países concluíram as alocações de espectro para o funcionamento da tecnologia $5 \mathrm{G}$, e 54 países anunciaram planos e datas aproximadas para alocar as frequências até o final do ano 2022.

$\mathrm{Na}$ Europa, vários países já concluíram os leilões para o uso do espectro de frequências a serem utilizadas na tecnologia 5G, são eles: Albânia, Áustria, Croácia, República Tcheca, Dinamarca, Finlândia, França, Alemanha, Grécia, Hungria, Irlanda, Itália, Letônia, Noruega e Eslováquia, Espanha, Suécia, Suíça e Reino Unido). Outros países como a Áustria, Bélgica, República Tcheca, Dinamarca, Estônia, Finlândia, França, Alemanha estimam ter seus leilões realizados até o ano de 2022 (GSA, 2020, tradução nossa).

$\mathrm{Na}$ Ásia-Pacífico, países como a Austrália, China, Hong Kong, Japão, Filipinas, República da Coréia e Tailândia já existem frequências definidas e leiloes anunciados.

Nas Américas, os Estados Unidos da América (EUA) divulgaram o espectro que será potencialmente utilizado para a alocação do 5G. Outros países americanos, como o Canadá, Colômbia, El Salvador, México e Uruguai já finalizaram as alocações dos espectros de frequências, e alguns já anunciaram as datas para os leilões, como é o caso da Argentina, Brasil, Canadá, Chile, Equador, El Salvador, México, Peru e, o próprio EUA (GSA, 2020, tradução nossa).

No Brasil, no dia 12 de março de 2020, foi realizada uma audiência pública sobre o leilão de $5 \mathrm{G}$ pela ANATEL por meio do Edital de Licitação para frequências de $700 \mathrm{MHz}, 2,3$ GHz, 3,5 GHz e $26 \mathrm{GHz}$. O Aviso da Audiência Pública foi publicado no Diário Oficial da União na quarta-feira, 4 de março (ANATEL, 2020).

Um dos receios da ANATEL (Agência Nacional de Telecomunicações), é que frequências sugeridas pelo ITU para o $5 \mathrm{G}$, já estejam em uso no Brasil, como por exemplo, o sinal do Satélite Geoestacionário de Defesa e Comunicações (SGDC), lançado pela Telebrás no ano de 2017, que utiliza as faixas de frequências desejadas pelos países da Europa (LIMA, 2018).

Segundo o Lima (2018), as frequências são finitas e grande parte delas já está em uso, então é preciso otimizar. Lima ressalta ainda, que os maiores fabricantes de interfaces para dispositivos móveis do mundo, já realizam testes em seus equipamentos, como é caso da fábrica de chips para celulares e carros inteligentes Qualcomm ${ }^{\circledR}$. 


\section{POSSÍVEIS IMPACTOS NEGATIVOS RELACIONADOS À TECNOLOGIA 5G}

Segundo o site BBC (2019), as redes 5G dependem de sinais de rádio por meio de ondas eletromagnéticas, assim como nas tecnologias móveis anteriores. Ondas eletromagnéticas também estão presentes nos serviços de rádio e televisão, assim como em várias outras tecnologias, incluindo os smartphones.

A tecnologia 5G usa ondas eletromagnéticas de frequências mais altas quando comparadas com as tecnologias móveis anteriores, o que permite que um maior volume de dispositivos tenha acesso à rede. Frequências altas possibilitam também o aumento da velocidade de conexão. As frequências altas percorrem distâncias mais curtas e desta forma, necessitam de mais antenas e equipamentos de propagação de sinais, quando comparados com as tecnologias anteriores (BBC, 2019).

De acordo com Mitsuura (2019), do site Extra, a organização responsável pela regulação de alimentos e medicamentos FDA, sigla em inglês (Food and Drug Administration - Administração de Medicamentos e Alimentos), até agora não encontrou indicativos de problemas de saúde relacionados à exposição às ondas de radiofrequência. Entretanto, um estudo feito pelo Programa Nacional de Toxicologia dos EUA, conclui que altos níveis de radiação de radiofrequência resultou em tumores em ratos.

[...] no experimento com ratos e camundongos, os níveis de exposição foram de 1,5 a 6 watts por quilograma em camundongos e de 2,5 a 10 watts por quilograma em ratos, ao longo de nove horas diárias. Foram testadas frequências e modulações das redes 2G, 3G, 4G, 4G-LTE e 5G. As conclusões apontaram "clara evidência de tumores no coração em ratos machos; e algumas evidências de tumores no cérebro e na glândula adrenal de ratos machos". Camundongos e ratos fêmeas não foram afetados, e os cientistas envolvidos destacam que os resultados não podem ser extrapolados para humanos (MITSUURA, 2019).

O estudo realizado pelo Programa Nacional de Toxicologia dos EUA descreve que: “apesar de nós não termos encontrado uma associação positiva, o fato de termos observado uma indicação de um aumento do risco no grupo com exposição à radiofrequência mais recente merece mais investigações.” (MITSUURA, 2019).

Segundo Oelinton (2019), do site Suprimatec, a tecnologia 5G pode ser prejudicial à vida de outros seres vivos. A reportagem publicada mostra que, em um parque na Holanda, cerca de 150 pássaros foram encontrados mortos. No local, havia um mastro 5G com uma frequência de pico de 7,40GHz. As aves que caíram maciçamente no chão, seriam vítimas de um experimento da tecnologia 5G, realizado no dia 30 de outubro de 2018, conforme Figura 2. 
Figura 2 - Mortes de pássaros na Holanda

\section{Experimento $5 G$ deixa centenas de aves mortas na Holanda}

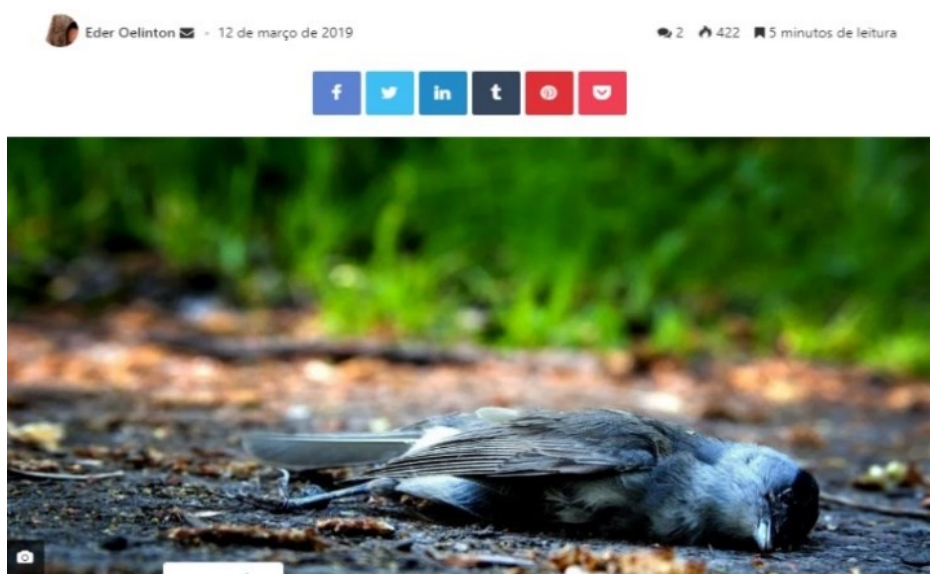

Fonte: Suprimatec (2019)

Após o caso, estudos realizados com os pássaros mortos comprovaram que eles estavam com os corpos saudáveis, sem qualquer sinal de vírus, infecção bacteriana, e tinham o sangue saudável e isento veneno. A única explicação razoável seria que o teste de operação de $5 \mathrm{G}$ teria afetados as aves (OELINTON, 2019).

Em outros locais como na Vila de Loppersum de Groningen, também na Holanda, animais apresentaram estranhos comportamentos enquanto era testada a tecnologia $5 \mathrm{G}$. $\mathrm{Na}$ Suíça um rebanho completo de vacas tombou em uma ravina, também enquanto testes de $5 \mathrm{G}$ eram realizados (OELINTON, 2019).

O governo do Reino Unidos diz que mesmo que seja possível um pequeno aumento na exposição geral às ondas de rádio $5 \mathrm{G}$, a expectativa é que a exposição geral permaneça baixa, pois a faixa de frequência emitida pelo $5 \mathrm{G}$, está dentro da banda não ionizante do espectro eletromagnético e bem abaixo dos níveis considerados danosas pela ICNIRP - International Commission on Non-Ionizing Radiation Protection (Comissão Internacional de Proteção contra Radiação Não Ionizante), (BBC, 2019).

Uma outra questão a ser considerada são as frequências propostas na padronização IMT-2020, em andamento pela ITU. De acordo com Baptista (2019), do site Tudo Celular, interferências foram constatadas em alguns serviços em funcionamento, como por exemplo, o serviço TV via satélite.

Segundo Amaral (2019), do Site Teletime, umas das faixas de frequência escolhidas para a transmissão do $5 \mathrm{G}$, é a $28 \mathrm{GHz}$ que já é atribuída para os satélites conforme resolução 
676/2017 da ANATEL. O Sindicato Nacional das Empresas de Telecomunicações por Satélite - SINDISAT cita iniciativas pelos EUA, Canadá e pelo ITU, reconhecendo a necessidade de adequação desse tipo de infraestrutura para a nova tecnologia.

Segundo Baptista (2019), do site Tudocelular, a interferência do 5G nos sinais de antena parabólica pode acarretar custos que podem chegar à bilhões de reais. De acordo com o levantamento, a instalação de filtros nas atuais parabólicas tem custo estimado de R\$460 milhões, enquanto a migração dos telespectadores da TVRO, como são chamadas, para a banda Ku custaria R\$ 9,6 bilhões. Já a ABRATEL (Associação Brasileira de Rádio e Televisão), entidade que possui algumas emissoras de TV aberta, estima o gasto de R \$ 2,9 bilhões.

Segundo Filho e Schaeffe (2019), como mostrado no site Olhardigital , as operadoras de telecomunicações Oi, Tim e Vivo se manifestaram a favor da prorrogação do leilão do 5G, dando mais tempo para que possam ser revistas as regras para que sejam mais favoráveis para setor e contribuindo para as empresas "tomarem um folego" após grande investimento no 4G. Mesmo assim o Ministério da Economia insiste na pressa da implementação, estimando que o 5G pode agregar R\$ 249 bilhões no PIB (Produto Interno Bruto).

\section{MATERIAIS E MÉTODOS}

A metodologia de pesquisa desse artigo foi baseada na pesquisa bibliográfica com o intuito de demostrar os possíveis impactos da tecnologia de rede móvel 5G, apresentando informações sobre a padronização do IMT-2020 definido pela União Internacional de Telecomunicações - ITU, por meio de pesquisa exploratória e analítica, bem como um estudo descritivo, que abrange os requisitos necessários para a implantação da tecnologia 5G.

Uma pesquisa bibliográfica envolve a busca de informações bibliográfica, seleção de documentos que se relacionam com o problema de pesquisa (livros, verbetes de enciclopédia, artigos de revistas, trabalhos de congressos, teses etc.) e o respectivo fichamento das referências para que sejam posteriormente utilizadas (MACEDO, 1996, p.13)

A abordagem desta metodologia é qualitativa, em que se demonstra o estudo e entendimento do $5 \mathrm{G}$, por meio de um ponto de vista amplo sobre o assunto abordado.

Uma abordagem qualitativa e não experimental que faz apelo as estudo exaustivo de caso para chegar à formulação de explicações casuais (Deslaurier, 1977, p.295), concluindo com uma definição sua: <<Indução analítica e um modo de colheita e análise dos dados que tem como finalidade clarificar os elementos fundamentais de 
um fenómeno e deduzir, se e possível, uma explicação universal >>(Deslaurier, 1977, p.295-296), (GUERRA, 2006, p.23).

\section{CONSIDERAÇÕES FINAIS}

A tecnologia de rede móvel causou grande mudança na sociedade em cada uma das suas gerações, demostrando a grande importância para a alteração no cenário da tecnologia, possibilitando inovações e crescimento em diversas áreas. Nesse sentido, com a chegada da tecnologia $5 \mathrm{G}$, pode-se esperar grandes mudanças tecnológicas no que se refere a novos tipos de serviços, como também, novos produtos.

Após a análise realizada do material bibliográfico, fonte de pesquisa deste artigo, algumas considerações se fazem necessárias:

- A tecnologia 5G possibilitará uma evolução em vários setores e aplicações;

- A tecnologia 5G proporcionará aos usuários uma maior conectividade de dispositivos a uma infraestrutura que permitirá maiores velocidades de conexões e baixa latência;

- A tecnologia 5G é a tecnologia que permitirá que cidades comuns se tornem cidades mais tecnológicas, podendo alcançar o título de cidades inteligentes;

- Como toda nova tecnologia, o estudo dos possíveis impactos negativos ainda está sendo mensurados por órgãos competentes;

- Como a padronização ainda não foi finalizada pela ITU, países em todo o mundo fazem o uso da autonomia, a que têm direito, e já realizaram leilões do espectro de frequência ou estão em fase de ajustes para a ocorrência destes, independentemente da padronização a ser concluída pela ITU. E o Brasil segue nessa mesma direção.

Este trabalho visou contribuir para o entendimento da tecnologia $5 \mathrm{G}$ no que se refere à regulamentação proposta pela ITU e pela ANATEL. Neste trabalho, também foi observada a importância da tecnologia 5G para o impulsionamento do conceito de Internet das Coisas. E, por fim, foram demonstrados alguns possíveis problemas relacionados aos seres vivos e interferências em serviços em funcionamento no Brasil, o que levou a ANATEL ao uso de algumas frequências fora do padrão ainda em desenvolvimento pela ITU. 


\section{REFERÊNCIAS}

ANATEL. Audiência pública sobre leilão de 5G da Anatel ocorre amanhã (12/3). 2020. Disponível em: $<$ https://www.anatel.gov.br/institucional/mais-noticias/2520-audienciapublica-sobre-leilao-de-5g-anatel-ocorre-amanha-12-3>. Acesso em: 23.mai. 2020

BBC. A radiação da tecnologia 5G faz mal à saúde?.2019. Disponível em: $<$ https://www.bbc.com/portuguese/geral-48987729>. Acesso em: 19.set.2019.

ETSI. why do we need 5g. 2019. Disponivel em:

$<$ https://www.etsi.org/technologies/5g?jjj=1567981299904. . . Acesso em: 08.set. 2019.

EXTRA.O 5G causa câncer? Saiba o que dizem os especialistas. 2019. Disponível em: < https://extra.globo.com/noticias/celular-e-tecnologia/o-5g-causa-cancer-saiba-que-dizem-osespecialistas-23430568.html>. Acesso em:19.mai.2020.

GSA. 5G Spectrum Report: February 2020. 2020.Disponível em: $<$ https://gsacom.com/paper/5g-spectrum-report-february-2020/>. Acesso em: 23.mai.2020

GSMA. Mobile IoT and 5G: Complementary Technologies Central to the IoT.

2018. Disponivel em: < https://www.gsma.com/iot/news/mobile-iot-and-5g-complementarytechnologies-central-to-the-iot/ >. Acesso em: 22 out. 2019.

GUERRA, Isabel C. Pesquisa Qualitativa e Análise de Conteúdo: Sentido e Formas de Uso. 1. ed. São João do Estoril: Princípia Editora, 2006.

IEEESPECTRUM.THE RACE TO 5G.2020.Disponível em:< https://spectrum.ieee.org/static/the-race-to-5g>. Acesso em: 24.mai.2020.

ITU. Abaut ITU Telecom. Disponivel em:

$<$ https://www.itu.int/en/itutelecom/Pages/default.aspx\#TOP>.2019.Acesso em:04.set.2019

ITU. 5G: Fifth generation of mobile technologies. 2019. Disponível em:

$<$ https://www.itu.int/en/mediacentre/backgrounders/Pages/5G-fifth-generation-of-mobiletechnologies.aspx $>$. Acesso em: 04. set. 2019.

LIMA. Conexão 5G ainda precisa ser padronizada por agência da ONU. 2018. Disponível em: $<$ https://link.estadao.com.br/noticias/geral,conexao-5g-ainda-precisa-serpadronizada-por-agencia-da-onu,70002556239>. Acesso em: 11. set. 2019.

MACEDO, Neusa D. Iniciação à Pesquisa Bibliográfica. 2. ed. São Paulo: Unimarco Editora, 1996.

OLHARDiGitAL. Oi, Tim e Vivo defende adiamento do leilão 5G no Brasil. 2019. Disponível em: $<$ https://olhardigital.com.br/noticia/oi-tim-e-vivo-defendem-adiamento-doleilao-5g-no-brasil/92443>. Acesso em: 07.nov. 2019. 
SUPRIMATEC. Experimento 5G deixa centenas de aves mortas na Holanda. 2019. Disponível em: $<$ https://suprimatec.com/experimento-5g-deixa-centenas-de-aves-mortas-naholanda/>. Acesso em: 25. set. 2019.

TELECO. 5G:Tecnologias de Celular. 2018. Disponível em:

$<$ https://www.teleco.com.br/5g_tecnologia.asp>. Acesso em: 16.set. 2019.

TELESÍNTESE. Europa harmoniza uso do espectro de 26 GHZ para 5G.2019. Disponível em: $<$ http://www.telesintese.com.br/europa-harmoniza-uso-do-espectro-de-26-ghz-para-5g/> Acesso em: 21. fev. 2020.

TELETIME. Setor de satélites se defende e diz ser vital para o 5G. 2019. Disponível em: $<$ https://teletime.com.br/09/08/2019/setor-de-satelites-se-defende-e-diz-ser-vital-para-o5g/>Acesso em: 12.out. 2019.

TUDOCELULAR. 5G no Brasil: conflito com TV via satélite pode custar prejuízo bilionário ao país. 2019. Disponível em: $<$ https://www.tudocelular.com/mercado/noticias/n147338/5gbrasil-conflito-tv-parabolica-prejuizo-bilhoes.html>. Acesso em: 12. out. 2019.

UOL. 3 grandes vantagens do 5G que mudarão para sempre nossa experiência na Internet.2019. Disponível em: $<$ https://www.uol.com.br/tilt/noticias/bbc/2019/06/03/3grandes-vantagens-do-5g-que-mudarao-para-sempre-nossa-experiencia-na-Internet.htm $>$. Acesso em: 04. set. 2019. 